\title{
NASAL SARCOMA, WITH REPORT OF A CASE.
}

\author{
BY J. $A$. WAISON, MID., MLLNEANOLIS.
}

In an article* on nasal sarcomn, published in $A$ pril, 1904, the writer reported four cases of this clisense. He has since observed a fifth, the history of which is herewith recorded.

Mrs. H. L., age 44, consulted me in February, 1905. She complained of not being able to breathe through the right nostril. The obstruction had commencer! nine years previously, and had slowly but stcadily progressed. During the last few years, she often had hemorrlages from that side of the nose, and of late they had been more frequent and more severe. 'Tor two or three years past, she had suffered severe and frefuent pain in the right side of the nose and face.

The patient had never been in robust health. Her mother died of consumption at forty-five. Her father died at scventy-six, she believed of some growth in the stomach. One sister was operated on at the nge of thirty-five for cancer of the breast. These are apparently the only facts in the family history that might have any bearing on the casc, all her other near relatives being healthy and long lived.

The patient was fairly well nourished. There was no appearance of cachexia. There was an evident, though not very marked, external deformity, the right side of the nose, including the nasal bone and nasal process of the superior maxillary bone being clisplaced outward. There was no apparent displacement of the anterior antral wall.

Anterior rhinoscopic examination revealed the presence of a growth filling all the lower part of the nasal fossa anteriorly. It conld not be observed in the post nasal mirror. The septum was pushed to the left. The growth was slightly movable, and careful cxamination with thic probe revealed the fact that it had an apparcitly pedunculated attachment to the septum. It was of firm consistency and dark brownish red color. The growth was casily and completely renioved at the first attempt with the cold wire snare and proved to be about the size of an ordinary English walnut. There was practically no bleeding, partly, no doubt, because the growth was sẹvered directly through its narrow pedicle. The

\footnotetext{
* Sarcoma of the Nasal l'assages, et ., Am. Afed., April 2, 1904.
} 
patient suffered no inconvenience cluring or after the operation. There has been no recurrence in eighteen months.

The following is the palhologist's report: "The section is of cartilage in which are'found many places where the cartilage has become supplanted by irregular areas containing round cells, between which is seen a variable amount of intracellular tissue. Many places show islands of cartilage isolated by the sarcoma cells. Numerous areas in both sarcomatous and cartilaginous elements show myxomatous degeneration. Diagnosis, Chondro sarcoma." This examination and report were made by Dr. Louis Dumn, of the pathological department of Hamline University.

This case substantiates the opinion expressed by the writer in his former article, that, contrary to the opinion of certain eninent authorities intranasal operation is justifiable in many, if not in most cases, of sarcoma of the nasal passages. He believes, in short, that intranasal operation is indicated in nearly all cases where the growth has an apparently limited area of attachment, and is manifestly confined to the nasal passages proper, without involvement of the sinuses. At an early stage of their growth most cases conform to this description. Nevertheless. the statement is not that all, but that nearly all such cases may properly be operated upon intranasally, since there is no doubt but that a case may exhibit stch evidences of malignancy as to well "give us pause". I am inclined to the opinion, however, that in such rare instances, for it will be remembered that excessive malignancy is rare in the case of nasal sarcoma, the dilemma is not so much whether we shall operate intranasally or extranasally, but rather whether we shall operate intranasally or at all.

On the other hand, I believe that involvment of the antrum of Highmore is not always an absolute contraindication to intranasal operation. Provicled it can be established with a fair degree of probability that the other sinuses are not involved and that the involvement of the antrum is really secondary, as incled it ustually is, we are justified in operating tentatively, since we will probably find that the antral walls are not involved, and that the growth, being merely a prolongation of that in the nasal fossa, can be pulled away. cu massc. Casc 2 of the series reported in my original article was a typical one of this variety, and was cured by intranasal operation. In advanced cases of this kind, access to the antrum is usually easy for the reason that the partition separating the two cavities is likely to have largely disappeared by pressure necrosis. But even should the operation reveal the fact that the growth is more than a 
mere prolongation, and that the walls of this cavity are actually involved in the pathologic process, there is no greater difficulty in removing the superior maxilla than before the intranasal operation was undertaken. The surgeon who has been wise enough to previously inform his patient as to the possibilities of the situation has not in any way compromised his reputation.

The classical symptoms of nasal sarcoma were manifested in the usual order in this case, viz: nasal obstruction, hemorrhage, pain, deformity, an order of occurrence which, as pointed out in my original article, is not without some suggestive bearing on the question of the site of origin and the progress of these growths. An inquiry into the probability of this growth having been originally pure chondroma would be perhaps interesting, but fruitless. The author still believes in the possibility of such transformation.

I034 Andrus Building.

Tubercular Laryngitis. A Plea for Early Recognition and Treatment. L. C. Cisive, Medical Agc, December, 1905.

Primary infection is an acceptable fact to the author. This occurs through the lymph channels from the pharyngeal, fancial or lingual tonsils, or from some other part of the upper respiratory or digestive tract. The larynx is the most frequent site of involvement. Chronic "catarrhal laryngit:s, with general impaired vitality, furnishes the most favorable conditions for the infection. Every country in the state should convert some of their beautiful hill lands into sanatoriums and equip them with every comfort and attraction. Those infected need to be educated at schools as to how the disease is contracted and how to get rid of it.

Stein. 